\title{
Personal Growth and Associated Factors Among Patients with Chronic Obstructive Pulmonary Disease in China: A Cross-Sectional Study
}

This article was published in the following Dove Press journal: International Journal of Chronic Obstructive Pulmonary Disease

\author{
Huimin Zhao' \\ Bei Wu (iD) ${ }^{2}$ \\ Linglin Kong \\ Junyao Fan' \\ Quan Wang' \\ Jie $\mathrm{Li}^{\prime}$ \\ Jing Mao iD \\ 'School of Nursing, Tongji Medical \\ College, Huazhong University of Science \\ and Technology, Wuhan, People's \\ Republic of China; ${ }^{2}$ Rory Meyers College \\ of Nursing and NYU Aging Incubator, \\ New York University, New York, \\ NY, USA
}

\begin{abstract}
Purpose: This cross-sectional study aimed to describe personal growth and to analyze its associated factors among patients with chronic obstructive pulmonary disease (COPD) in China.
\end{abstract}

Patients and Methods: A total of 364 Chinese COPD hospitalized patients were included in the study between November 2016 and April 2018. Participants provided demographic information and completed the Growth Through Uncertainty Scale (GTUS), the Multidimensional Scale of Perceived Social Support (MSPSS), and the modified Medical Research Council dyspnoea scale (mMRC).

Results: The mean total score on the GTUS was $142.34(S D=7.61)$. The multiple linear regression analysis showed that factors including educational level, average monthly income, social support, and breathlessness can influence personal growth $\left(R^{2}=0.427, F=44.420, p<\right.$ 0.001 ), explaining $42.7 \%$ of the variance.

Conclusion: COPD patients tend to report a moderate level of personal growth in China. Educational level, average monthly income, social support, and breathlessness were significant factors associated with personal growth. Medical workers should be aware of the level of personal growth among COPD patients and make tailored interventions to facilitate COPD patients' personal growth, such as increasing social support and decrease breathlessness.

Keywords: breathlessness, China, COPD, personal growth, social support

\section{Introduction}

Chronic obstructive pulmonary disease (COPD) is a common preventable and treatable disease characterized by persistent respiratory symptoms and airflow limitation that is not fully reversible. ${ }^{1}$ The predominant respiratory symptom of COPD is breathlessness, which varies in frequency, severity, and distress. Evidence suggested that the global prevalence of COPD was $11.7 \%$ in $2010 .^{2}$ Considering the aging of the world's population and the continued exposure to COPD risk factors, COPD prevalence is expected to increase in the coming decades. COPD is the third leading cause of global death and claimed 3.0 million lives in 2016. ${ }^{3}$ The direct medical cost of COPD varied from 72 to 3565 USD per capita per year, accounting for $33.33 \%$ to $118.09 \%$ of the local average annual income. ${ }^{4}$ Therefore, COPD remains an important public health problem.

Personal growth refers to individuals with chronic illness accepting continual uncertainty, integrating uncertainty into life, believing in a world without absolute certainty, and developing a new view of life based on the reconceptualization of the
Correspondence: Jie Li; Jing Mao School of Nursing, Tongji Medical College, Huazhong University of Science and Technology, Hangkong Road 13, Qiaokou District, Wuhan 430030, People's

Republic of China

Tel +86 I897|09709I; +86 I33|7|35988

Fax +86 02783692635; +86 02783692657

Email Lijie@hust.edu.cn; maojing@hust. edu.cn
International Journal of Chronic Obstructive Pulmonary Disease 2020:I 5 2977-2983

2977

DovePress $\mathbf{f}$ in $\boldsymbol{D}$ 
uncertainty in illness theory. ${ }^{5}$ Personal growth was measured by using the Growth Through Uncertainty Scale (GTUS), which was developed by Mishel and Fleury in 1997. ${ }^{6}$ The GTUS has been valid in breast cancer survivors, prostate cancer patients, postoperative colorectal cancer patients, and parents of children with acute leukemia. ${ }^{7-10}$ So far, there have been no studies using GTUS to assess COPD patients' personal growth.

Although there are some qualitative studies exploring personal growth, ${ }^{11-13}$ limited quantitative studies have been conducted on this topic. For instance, Overbaugh et al reported moderate levels of personal growth among patients with heart failure. ${ }^{14} \mathrm{Hu}$ et al found similar results in postoperative colorectal cancer patients. ${ }^{9}$ Tian et al indicated high levels of personal growth among parents of children with autism. ${ }^{15}$ To our knowledge, no quantitative studies have investigated the level of personal growth among COPD patients.

Personal growth was associated with many demographic variables, including age, ${ }^{16}$ sex, ${ }^{17,18}$ marital status, ${ }^{16,19}$ educational level, ${ }^{7,20}$ and economical status. ${ }^{21,22}$ Furthermore, a positive correlation was found between social support and personal growth. Patients with greater social support tended to experience greater personal growth than others. ${ }^{20,23}$ Despite the available evidence that personal growth is related to multiple predictors, the factors associated with personal growth in Chinese COPD patients have not been studied.

To address the above gaps, we conducted this crosssectional study. The purpose of this study was to quantitatively describe personal growth among Chinese COPD patients and to identify the factors associated with personal growth. This study will provide theoretical foundation for future research. This knowledge will help medical workers to understand COPD patients' personal growth and develop effective interventions to promote personal growth.

\section{Patients and Methods Design}

A cross-sectional survey was conducted from November 2016 to April 2018 in the wards of the respiratory departments of the following six hospitals in China: Tongji Hospital, Union Hospital, Liyuan Hospital, First Hospital of Shanxi Medical University, Second Hospital of Shanxi Medical University, and Shanxi Provincial People's Hospital.

\section{Participants}

COPD patients fulfilling the following inclusion criteria were recruited in this study: (1) being diagnosed with COPD by a physician, as documented on the patient's record, (2) age $>40$ years, (3) being able to communicate in Chinese, and (4) being willing to participate in this study. Patients with cognitive impairment or psychiatric diseases were excluded.

\section{Measures}

All eligible participants were informed about the aims of the study and the study procedures. All participation was voluntary and anonymous. The well-trained investigators obtained written informed consent and collected selfreport questionnaires from all the patients. The survey lasted approximately 30 minutes. Demographic data were collected, including age, sex, marital status, educational level, average monthly income, payment method for medical expenses, number of hospitalizations due to diagnosis of COPD, and comorbid chronic conditions.

Personal growth was assessed with GTUS. ${ }^{6}$ The GTUS was the first self-report scale to evaluate positive psychological changes and personal growth. It consists of 39 items, and each item is rated on a 6-point Likert scale from 1 (strongly disagree) to 6 (strongly agree) with 4 items being reverse scored. The total score ranges from 39 to 234 with higher scores representing more personal growth. ${ }^{6}$ The Cronbach's $\alpha$ coefficient of the GTUS was 0.66 in this study.

Social support was measured using the Multidimensional Scale of Perceived Social Support (MSPSS). ${ }^{24}$ The MSPSS was designed to evaluate the perceived social support from family, friends, or significant others, and it comprises 12 items and three subscales. ${ }^{24}$ Each subscale includes 4 items that are rated using a 7-point Likert scale from 1 (strongly disagree) to 7 (strongly agree). The subscale scores range from 4 to 27, and the total score ranges from 12 to 84 with higher scores indicating greater perceived social support. ${ }^{25}$ Cronbach's alpha for the MSPSS in patients with comorbid COPD and heart failure was $0.93 .{ }^{26}$ The Cronbach's $\alpha$ coefficient of the MSPSS was 0.71 in this study.

Breathlessness was evaluated by the modified Medical Research Council dyspnoea scale (mMRC) with scores ranging from 0 to $4 .{ }^{27} \mathrm{~A}$ higher score indicates more breathlessness. ${ }^{27}$

\section{Ethical Considerations}

This study was approved by the Institutional Review Board of Tongji Medical College, Huazhong University of Science 
and Technology. Permission to recruit participants was granted from the administrators of the six hospitals before data collection commenced. The study was conducted in accordance with the Declaration of Helsinki. The study was reported in compliance with the Strengthening the Reporting of Observational Studies in Epidemiology (STROBE) recommendations (Table S1).

\section{Sample Size Calculation}

The sample size was at least ten times of the number of independent variables. ${ }^{28}$ While calculating the sample size, $10 \%$ none-response rate was considered. The minimum sample size was 110 in this study.

\section{Data Analysis}

Data were analyzed using the Statistical Package for Social Sciences, version 24.0 (IBM SPSS Corp). Normal distribution was evaluated with determination of histogram. Personal growth was considered normally distributed. Homogeneity of variance was determined by Levene's test. The variances were equal across groups. Descriptive statistics including means, standard deviations, frequencies, and percentages were calculated to summarize all the variables. Statistical methods included independent sample $t$-test, one-way ANOVA, Pearson correlation, and enter-method multiple linear regression analysis. Variables were included in enter-method multiple linear regression analysis if there was a significant association in independent sample $t$-test, one-way ANOVA, and Pearson correlation. Multicollinearity between independent variables was assessed by performing variance inflation factor (VIF) tests. $^{29}$ Generally, VIF values exceeding 10 indicate the presence of multicollinearity. ${ }^{29}$ In our study, VIF values were no greater than 1.610 for any variable. In all analyses, statistical significance was set at $p<0.05$.

\section{Results}

\section{Participant Characteristics, Personal Growth, Social Support, and Breathlessness}

The initial sample included a total of 403 COPD patients, of which 378 (93.8\%) patients agreeing to participate in the survey. Three hundred and sixty-four patients completed the survey questionnaire leading to an effective response rate of $90.3 \%$. The mean age of patients was 68.76 years $(S D=9.86)$ and ranging from 43 to 94 years. The sample consisted of $79.7 \%$ males and $20.3 \%$ females. $86.3 \%$ patients were married and $13.7 \%$ were widowed. The majority of participants had a middle level of education (55.5\%), followed by low education $(35.2 \%)$ and high education (9.3\%). 85.2\% patients reported an average income of 4999 RMB per month or below. The major payment method for medical expenses were the basic social medical insurance scheme for urban employees $(41.2 \%)$ and the new rural cooperative medical insurance scheme (31.9\%). The number of hospitalizations due to diagnosis of COPD ranged from 1 to 33 , with $78.0 \%$ having one or two hospitalizations. From the sample, $51.6 \%$ participants reported no comorbid chronic disease and $48.4 \%$ had at least one comorbid chronic disease.

The mean total score for the GTUS was 142.34 (SD = 7.61 ), the minimum score was 110 , and the maximum score was 164 in this study. The mean scores of the total MSPSS and on the subscales for family, friends, and significant others were $50.94(S D=7.83), 25.48(S D=2.54)$, $11.49(S D=4.54)$, and $13.96(S D=5.61)$, respectively. The mean mMRC score was $2.44(S D=0.76)$.

\section{Univariate Analysis}

A significant difference was found in the average GTUS score based on educational level, average monthly income, and payment method for medical expenses $(p<0.001)$ (Table 1).

\section{Correlational Analysis}

In the correlational analysis, age $(r=0.163, p<0.01)$, social support $(r=0.546, p<0.01)$, and breathlessness $(r=-0.501, p<0.01)$ were associated with personal growth.

\section{Multiple Regression}

Multiple regression analysis was performed based on statistically significant variables in univariate analysis and correlational analysis, including educational level, average monthly income, payment method for medical expenses, age, social support, and breathlessness. Educational level, average monthly income, social support, and breathlessness were significant factors associated with personal growth $\left(R^{2}=0.427, F=44.420, p<0.001\right)$, explaining $42.7 \%$ of the variance (Table 2 ).

\section{Discussion}

This study aimed to describe Chinese COPD patients' personal growth and identify its influencing factors. Overall, our results indicated a moderate level of personal 
Table I Comparison of Personal Growth According to Participant Characteristics

\begin{tabular}{|c|c|c|c|c|c|}
\hline \multicolumn{2}{|l|}{ Variables } & \multirow{3}{*}{$\begin{array}{l}\mathbf{n} \\
290 \\
74\end{array}$} & \multirow{3}{*}{$\begin{array}{l}\text { GTUS } \\
\text { Mean (SD) } \\
142.60(7.53) \\
|4| .3 \mid \text { (7.89) }\end{array}$} & \multirow{3}{*}{$\begin{array}{l}\boldsymbol{t} / \mathbf{F} \\
1.306\end{array}$} & \multirow{3}{*}{$\begin{array}{l}p \\
0.193\end{array}$} \\
\hline Sex & Male & & & & \\
\hline & Female & & & & \\
\hline \multirow[t]{2}{*}{ Marital status } & Married & 314 & 142.15 (7.87) & -1.180 & 0.239 \\
\hline & Widowed & 50 & $143.52(5.64)$ & & \\
\hline \multirow[t]{3}{*}{ Educational level } & Low education & 128 & $139.45(5.63)$ & 27.950 & $<0.001$ \\
\hline & Middle education & 202 & 143.00 (7.99) & & \\
\hline & High education & 34 & $\mid 49.32(6.4 \mid)$ & & \\
\hline \multirow[t]{9}{*}{ Average monthly income (RMB) } & $<1000$ & 122 & $139.58(6.26)$ & 9.990 & $<0.001$ \\
\hline & $1000 \sim 1999$ & 28 & $138.18(7.61)$ & & \\
\hline & $2000 \sim 2999$ & 48 & $141.10(8.12)$ & & \\
\hline & $3000 \sim 3999$ & 68 & I 43.84 (8.47) & & \\
\hline & $4000 \sim 4999$ & 44 & $145.48(5.01)$ & & \\
\hline & $5000 \sim 5999$ & 26 & 144.62 (2.98) & & \\
\hline & $6000 \sim 6999$ & 6 & 148.17 (6.43) & & \\
\hline & $7000 \sim 7999$ & 6 & $151.17(4.22)$ & & \\
\hline & $8000 \sim 8999$ & 16 & $150.19(9.45)$ & & \\
\hline \multirow{8}{*}{$\begin{array}{l}\text { Payment method for medical } \\
\text { expenses }\end{array}$} & The basic social medical insurance scheme for urban employees & 150 & $|43.3|$ (8.09) & 5.631 & $<0.001$ \\
\hline & The basic social medical insurance for urban residents & 8 & $143.50(5.29)$ & & \\
\hline & The new rural cooperative medical insurance scheme & 116 & $139.14(7.16)$ & & \\
\hline & Medical assistance & 6 & $139.50(1.64)$ & & \\
\hline & Free medical service & 24 & 146.25 (6.29) & & \\
\hline & Out-of-pocket & 32 & I 44.47 (5.99) & & \\
\hline & Other social insurances & 8 & $144.13(6.70)$ & & \\
\hline & Others & 20 & $145.25(6.10)$ & & \\
\hline \multirow{13}{*}{$\begin{array}{l}\text { Number of hospitalizations due } \\
\text { to diagnosis of COPD }\end{array}$} & I & 226 & $|4| .87(8.32)$ & 1.265 & 0.238 \\
\hline & 2 & 58 & $|4| .24(5.77)$ & & \\
\hline & 3 & 26 & I 44.04 (8.66) & & \\
\hline & 4 & 14 & 142.07 (4.98) & & \\
\hline & 5 & 8 & I 46.88 (5.94) & & \\
\hline & 7 & 6 & I 45.67 (4.93) & & \\
\hline & 8 & 6 & 143.50 (3.08) & & \\
\hline & 9 & 2 & $139.50(0.7 \mid)$ & & \\
\hline & 10 & 6 & $143.67(3.14)$ & & \\
\hline & 12 & 6 & $149.00(2.37)$ & & \\
\hline & 18 & 2 & $144.00(0.00)$ & & \\
\hline & 30 & 2 & $\mid 45.50(0.7 \mid)$ & & \\
\hline & 33 & 2 & $150.00(0.00)$ & & \\
\hline \multirow[t]{5}{*}{ Comorbid chronic conditions } & 0 & 188 & $141.93(7.05)$ & 0.396 & 0.812 \\
\hline & 1 & 110 & $142.50(8.69)$ & & \\
\hline & 2 & 44 & $143.30(6.91)$ & & \\
\hline & 3 & 20 & $143.10(8.4 I)$ & & \\
\hline & 4 & 2 & $144.00(0.00)$ & & \\
\hline
\end{tabular}

growth for COPD patients in China. The mean total score on the GTUS was $142.34(S D=7.61)$, which was lower than that reported in previous studies. ${ }^{10,30-32}$ This discrepancy may be explained that the samples are different between our study and others. We surveyed COPD patients, whereas other studies focused on cancer patients or parents of children with cancer. In terms of the severity of the disease, cancer may be more likely to cause death 
Table 2 The Results of Multiple Linear Regression Analysis for Explaining Personal Growth

\begin{tabular}{|c|c|c|c|c|c|c|c|}
\hline \multirow[t]{2}{*}{ Variables } & \multirow[t]{2}{*}{$\beta$} & \multirow[t]{2}{*}{ SEB } & \multirow[t]{2}{*}{$\beta^{\prime}$} & \multirow[t]{2}{*}{$t$} & \multirow[t]{2}{*}{$p$} & \multicolumn{2}{|c|}{$95 \% \mathrm{Cl}$ for $\beta$} \\
\hline & & & & & & Lower & Upper \\
\hline Educational level & 2.059 & 0.585 & 0.167 & 3.522 & $<0.001$ & 0.909 & 3.209 \\
\hline Average monthly income & 0.508 & 0.175 & 0.148 & 2.909 & 0.004 & 0.165 & 0.851 \\
\hline Social support & 0.333 & 0.047 & 0.343 & 7.165 & $<0.001$ & 0.242 & 0.425 \\
\hline Breathlessness & -2.287 & 0.486 & -0.227 & -4.708 & $<0.001$ & -3.242 & -1.332 \\
\hline
\end{tabular}

Abbreviations: $S E B$, standard error of beta; $\mathrm{Cl}$, confidence interval.

than COPD. Patients may experience greater personal growth if they suffer from more severe diseases. ${ }^{33}$

Using multiple linear regression, educational level, average monthly income, and social support were identified as influencing factors of personal growth in our study.

The current study demonstrated that educational level was a positive influencing factor of personal growth. Studies by Carol, Porter, and Sim have produced similar findings. 7,33,34 However, other studies reported that a higher educational level was less likely to influence personal growth than other educational levels..$^{22,35,36}$ In another study, educational level did not affect personal growth. ${ }^{37}$ Given the conflicting findings, further research is required to confirm the association between educational level and personal growth.

In addition to educational level, average monthly income emerged as one of the most important predictors of personal growth. In agreement with our study, previous studies have indicated that higher income was associated with greater personal growth. ${ }^{22,33,38}$ One possible explanation for this result may be that patients with higher incomes may prefer to seek high-quality treatment and thus suffer less hardships than those with lower incomes. In contrast, patients with a lower income are at risk of confronting economic burden and experiencing more stress due to their illness than those with higher incomes. ${ }^{39}$

This study confirmed previous findings that personal growth was positively associated with social support, ${ }^{20,40,41}$ showing that greater perceived social support predicted higher levels of personal growth. Social support may reduce patients' isolation and stigma by giving emotional, social, informational and practical help. ${ }^{42}$ In addition, social support may provide coping strategies for stress related to disease and facilitate personal growth. $^{43}$ In our study, COPD patients' social support was mainly obtained from family. It is possible that patients were mostly retirees and had little communication with friends. This finding indicates that the development of interventions to enhance social support for COPD patients, especially from friends and significant others, can improve their personal growth.

The present study offered preliminary insights into the relationships between breathlessness and personal growth among COPD patients. This study showed that COPD patients experiencing less breathlessness reported greater personal growth. To date, this study is the first to examine the relationship between personal growth and breathlessness. Thus, this result was viewed as tentative. Further studies in this area are warranted.

This study has several strengths. This study included a large sample with a high response rate and was performed in six hospitals across China between November 2016 and April 2018, which may generalize the findings. Furthermore, on-site data collection conducted by well-trained investigators promoted the validity and reliability of the results.

Several potential limitations should be noted in the present study. First, our study was designed as a crosssectional survey, preventing us from determining the causal relationships between personal growth and the associated factors. Second, the reliabilities of GTUS and MSPSS were not high, which may increase measurement error and to some extent reduce the overall power of the study. Third, the use of convenience sampling may devalue the representativeness of the sample and limit the generalizability of the findings. Finally, although some related variables were investigated in the study, this survey did not consider patients' other characteristics, such as employment status, religious beliefs, disease severity, and coping strategies.

This study provides the following suggestions for future research. First, longitudinal studies are needed to establish causality for this topic. Second, future studies are required to further assess and improve the reliabilities of GTUS and MSPSS among COPD patients in China. Third, further research should use random sampling to reduce 
selection bias and minimize the weaknesses in the study design. Fourth, employment status, religious beliefs, disease severity, and coping strategies should be included as influencing factors of personal growth in future studies.

\section{Conclusion}

COPD patients experienced a moderate level of personal growth in China. Educational level, average monthly income, social support, and breathlessness were significantly associated with personal growth. Therefore, we suggest that healthcare professionals pay attention to COPD patients' positive psychological changes and take effective measures to improve patients' social support and decrease breathlessness, thereby promoting their personal growth.

\section{Acknowledgments}

The authors would like to thank the hospital administrators who facilitated the survey for their efforts, and we also appreciate all the COPD patients who participated in this study.

\section{Disclosure}

The authors declare no conflicts of interest.

\section{References}

1. Global Initiative for Chronic Obstructive Lung Disease [homepage on the Internet]. Global strategy for the diagnosis, management and prevention of chronic obstructive pulmonary disease (2020 report); 2020. Available from: https:/goldcopd.org/wp-content/uploads/2019/12/ GOLD-2020-FINAL-ver1.2-03Dec19_WMV.pdf. Accessed September 15, 2020.

2. Adeloye D, Chua S, Lee C, et al. Global and regional estimates of COPD prevalence: systematic review and meta-analysis. $J$ Glob Health. 2015;5(2):1-17. doi:10.7189/jogh.05-020415

3. World Health Organization [homepage on the Internet]. The top 10 causes of death; 2018. Available from: https://www.who.int/en/newsroom/fact-sheets/detail/the-top-10-causes-of-death. Accessed May 24, 2018.

4. Zhu BF, Wang YF, Ming J, Chen W, Zhang LY. Disease burden of COPD in China: a systematic review. Int J Chron Obstruct Pulmon Dis. 2018;13:1353-1364. doi:10.2147/COPD.S161555

5. Mishel MH. Reconceptualization of the uncertainty in illness theory. Image J Nurs Sch. 1990;22(4):256-262. doi:10.1111/j.1547-5069.19 90.tb00225.x

6. Mishel MH, Fleury J. The Growth Through Uncertainty Scale. Unpublished Manuscript. The University of North Carolina at Chapel Hill; 1997.

7. Porter LS, Clayton MF, Belyea M, Mishel M, Gil KM, Germino BB. Predicting negative mood state and personal growth in African American and White long-term breast cancer survivors. Ann Behav Med. 2006;31(3):195-204. doi:10.1207/s15324796abm3103_1

8. Bailey DE, Mishel MH, Belyea M, Stewart JL, Mohler J. Uncertainty intervention for watchful waiting in prostate cancer. Cancer Nurs. 2004;27(5):339-346. doi:10.1097/00002820-200409000-00001
9. Hu SH, Wang WL, Pan Q, Zuo XF, Fang Y. Study on the relationship among uncertainty, coping styles and personal growth of the postoperative colorectal cancer patients undergoing chemotherapy. Chin J Mod Nurs. 2014;20(35):4433-4436. doi:10.3760/cma.j.issn.1674-2907.2014.35.009

10. He S, You LM, Zheng J, Bi YL. Uncertainty and personal growth through positive coping strategies among Chinese parents of children with acute leukemia. Cancer Nurs. 2016;39(3):205-212. doi:10.1097/ NCC.0000000000000279

11. Bahrami M, Taleghani F, Loripoor M, Yousefy A. Positive changes after breast cancer: a qualitative study. J Educ Health Promot. 2015;4 (1):55. doi:10.4103/2277-9531.162353

12. Parry C. Embracing uncertainty: an exploration of the experiences of childhood cancer survivors. Qual Health Res. 2003;13(2):227-246. doi: $10.1177 / 1049732302239600$

13. Waizbard-Bartov E, Yehonatan-Schori M, Golan O. Personal growth experiences of parents to children with autism spectrum disorder. J Autism Dev Disord. 2019;49(4):1330-1341. doi:10.1007/s10803018-3784-6

14. Overbaugh KJ, Parshall MB. Personal growth, symptoms, and uncertainty in community-residing adults with heart failure. Heart Lung. 2017;46(1):54-60. doi:10.1016/j.hrtlng.2016.09.002

15. Tian HY, Zhang XL, Bin J. Relationship between coping style and mental growth of parents in autistic children. J Qilu Nurs. 2018;24 (21):19-22. doi:10.3969/j.issn.1006-7256.2018.21.006

16. Mystakidou K, Tsilika E, Parpa E, Kyriakopoulos D, Malamos N, Damigos D. Personal growth and psychological distress in advanced breast cancer. Breast. 2008;17(4):382-386. doi:10.1016/j.breast.2008. 01.006

17. Leong Abdullah MFI, Hami R, Appalanaido GK, Azman N, Mohd Shariff N, Md Sharif SS. Diagnosis of cancer is not a death sentence: examining posttraumatic growth and its associated factors in cancer patients. J Psychosoc Oncol. 2019;37(5):636-651. doi:10.1080/0734 7332.2019.1574946

18. Albuquerque S, Narciso I, Pereira M. Posttraumatic growth in bereaved parents: a multidimensional model of associated factors. Psychol Trauma. 2018;10(2):199-207. doi:10.1037/tra0000305

19. Bellizzi KM, Blank TO. Predicting posttraumatic growth in breast cancer survivors. Health Psychol. 2006;25(1):47-56. doi:10.1037/ 0278-6133.25.1.47

20. Barraza Illanes P, Calvo-Francés F. Predictors of personal growth in induced abortion. Psicothema. 2018;30(4):370-375. doi:10.7334/ psicothema2018.65

21. Ho S, Rajandram RK, Chan N, Samman N, McGrath C, Zwahlen RA. The roles of hope and optimism on posttraumatic growth in oral cavity cancer patients. Oral Oncol. 2011;47 (2):121-124. doi:10.1016/j.oraloncology.2010.11.015

22. Lu PW. Personal Growth and Associated Factors Among Parents of Children with Rheumatic Diseases: A Cross-Sectional Study [Dissertation]. Beijing: Chinese Academy of Medical Sciences \& Peking Union Medical College; 2016.

23. Ott CH, Sanders S, Kelber ST. Grief and personal growth experience of spouses and adult-child caregivers of individuals with Alzheimer's disease and related dementias. Gerontologist. 2007;47(6):798-809. doi:10.1093/geront/47.6.798

24. Zimet GD, Powell SS, Farley GK, Werkman S, Berkoff KA. Psychometric characteristics of the multidimensional scale of perceived social support. J Pers Assess. 1990;55(3-4):610-617. doi:10.1080/00223891.1990.9674095

25. Dahlem NW, Zimet GD, Walker RR. The multidimensional scale of perceived social support: a confirmation study. J Clin Psychol. 1991;47(6):756-761. doi:10.1002/1097-4679(199111)47:6<756::aidjclp2270470605>3.0.co;2-1

26. Bugajski A, Frazier SK, Moser DK, Lennie TA, Chung M. Psychometric testing of the multidimensional scale of perceived social support in patients with comorbid COPD and heart failure. Heart Lung. 2019;48(3):193-197. doi:10.1016/j.hrtlng.2018.09.014 
27. Bestall JC, Paul EA, Garrod R, Garnham R, Jones PW, Wedzicha JA Usefulness of the medical research council (MRC) dyspnoea scale as a measure of disability in patients with chronic obstructive pulmonary disease. Thorax. 1999;54(7):581-586. doi:10.1136/thx.54.7.581

28. Fang JQ. Health Statistics. 7th ed. Beijing: People's medical publishing house; 2016.

29. Allison PD. Logistic Regression Using the SAS System: Theory and Application. Cary: SAS Institute Inc; 1999.

30. Lin L, Yeh CH, Mishel MH. Evaluation of a conceptual model based on Mishel's theories of uncertainty in illness in a sample of Taiwanese parents of children with cancer: a cross-sectional questionnaire survey. Int J Nurs Stud. 2010;47(12):1510-1524. doi:10.10 16/j.ijnurstu.2010.05.009

31. Wang JX, Wang WL, Pan Q, Hong JF, Jin M. A structural equation model of personal growth among patients with gastrointestinal cancer undergoing chemotherapy. J Nurs Sci. 2014;29(5):53-56. doi:10.38 70/hlxzz.2014.05.053

32. Tan Y. Predictors of personal growth among parents of children with malignant lymphoma: a cross-sectional study. Lab Med Clin. 2017;14 (12):1795-1797. doi:10.3969/j.issn.1672-9455.2017.12.043

33. Sim BY, Lee YW, Kim H, Kim SH. Post-traumatic growth in stomach cancer survivors: prevalence, correlates and relationship with health-related quality of life. Eur J Oncol Nurs. 2015;19(3):230-236. doi:10.1016/j.ejon.2014.10.017

34. Carol DR. Happiness is everything, or is it? Explorations on the meaning of psychological well-being. J Pers Soc Psychol. 1989;57 (6):1069-1081. doi:10.1037/0022-3514.57.6.1069

35. Fox KR, Posluszny DM, DiMartini AF, et al. Predictors of post-traumatic psychological growth in the late years after lung transplantation. Clin Transplant. 2014;28(4):384-393. doi:10.1111/ ctr. 12301
36. Widows MR, Jacobsen PB, Booth-Jones M, Fields KK. Predictors of posttraumatic growth following bone marrow transplantation for cancer. Health Psychol. 2005;24(3):266-273. doi:10.1037/0278-61 33.24.3.266

37. Behzadi M, Rassouli M, Khanali Mojen L, Pourhoseingholi MA, Alaie Karahroudy F. Posttraumatic growth and its dimensions in the mothers of children with cancer. Int $J$ Community Based Nurs Midwifery. 2018;6(3):209-217.

38. Carpenter JS, Brockopp DY, Andrykowski MA. Self-transformation as a factor in the self-esteem and well-being of breast cancer survivors. J Adv Nurs. 1999;29(6):1402-1411. doi:10.1046/j.13652648.1999.01027.x

39. Kennedy K. Personal Growth in Couples Caring for a Child with a Life-Threatening Illness [Dissertation]. Waterloo: Wilfrid Laurier University; 2009.

40. Ekim A, Ocakci AF. Relationship between posttraumatic growth and perceived social support for adolescents with cancer. J Hosp Palliat Nurs. 2015;17(5):450-455. doi:10.1097/njh.0000000000000183

41. Prati G, Pietrantoni L. Optimism, social support, and coping strategies as factors contributing to posttraumatic growth: a meta-analysis. J Loss Trauma. 2009;14(5):364-388. doi:10.1080/153250209027 24271

42. Morris BA, Chambers SK, Campbell M, Dwyer M, Dunn J. Motorcycles and breast cancer: the influence of peer support and challenge on distress and posttraumatic growth. Support Care Cancer. 2012;20(8):1849-1858. doi:10.1007/s00520-011-1287-5

43. Duran B. Posttraumatic growth as experienced by childhood cancer survivors and their families: a narrative synthesis of qualitative and quantitative research. J Pediatr Oncol Nurs. 2013;30(4):179-197. doi:10.1177/1043454213487433

\section{Publish your work in this journal}

The International Journal of COPD is an international, peer-reviewed journal of therapeutics and pharmacology focusing on concise rapid reporting of clinical studies and reviews in COPD. Special focus is given to the pathophysiological processes underlying the disease, intervention programs, patient focused education, and self management protocols. This journal is indexed on PubMed Central, MedLine and CAS. The manuscript management system is completely online and includes a very quick and fair peer-review system, which is all easy to use. Visit http://www.dovepress.com/testimonials.php to read real quotes from published authors 